\title{
Factors Affecting Test Results and Standardized Method in Quiet Standing Balance Evaluation
}

\author{
Jung Joong Yoon, M.D., Tae Sik Yoon, M.D., Bo Mi Shin, M.D., Eun Hye Na, M.D.
}

Department of Rehabilitation Medicine, School of Medicine, Ewha Womans University, Seoul 158-710, Korea

Objective To identify factors affecting test results of the quiet standing balance evaluation conducted by posturography and to investigate the standardized method by comparing results according to feet width.

Method The study cohort consisted of 100 healthy individuals. We assessed the quiet standing balance of subjects by using 3 different methods: standing on a force plate with feet width the same as shoulder width (test 1); with feet width the same as half the shoulder width (test 2); with feet width determined by the subject's comfort (test 3 ). Subjects underwent each test with their eyes open and closed for 30 seconds each time. Parameters for measuring standing balance included the mean mediolateral and anteroposterior extent, speed, and the velocity moment of center of pressure (COP) movement.

Results All parameters showed better results when the subject's eyes were open rather than closed, and the mean AP extent and speed increased as the age of the subjects increased $(\mathrm{p}<0.01)$. However, there was no significant correlation between height and the study parameters, and no differences between men and women. Mean mediolateral extent and speed were significantly longer and faster in test 1 compared with tests 2 and $3(\mathrm{p}<0.01)$. The results of test 2 were better than the results of test 3 , but the difference was not statistically significant.

Conclusion COP movements increased with age and when subjects closed their eyes in an evaluation of quiet standing balance conducted by posturography. Gender and height did not affect results of the test. We suggest that an appropriate method for conducting posturography is to have the subject stand on a force plate with their feet width the same as half the shoulder width, because this posture provided relatively accurate balance capacity.

Key Words Balance, Evaluation, Method

Received August 30, 2011; Accepted October 12, 2011

Corresponding author: Tae Sik Yoon

Department of Rehabilitation Medicine, School of Medicine, Ewha Womans University, 911-1, Mok-dong, Yangcheon-gu, Seoul 158-710, Korea

Tel: +82-2-2650-5035, 6162, Fax:+82-2-2650-5145, E-mail: yoonreha@ ewha.ac.kr

(c) This is an open-access article distributed under the terms of the Creative Commons Attribution Non-Commercial License (http:// creativecommons.org/licenses/by-nc/3.0) which permits unrestricted noncommercial use, distribution, and reproduction in any medium, provided the original work is properly cited.

Copyright () 2012 by Korean Academy of Rehabilitation Medicine

\section{INTRODUCTION}

The body's center of gravity (COP) is located over the second sacral vertebra, and should remain inside the base of support to maintain static balance during quiet standing. Activities displacing the center of gravity, such as leaning, require dynamic balance, which returns the center of gravity to the second sacral vertebra over the base of support. This requires coordinated efforts involving the sensory systems (visual, vestibular, and proprioceptive) and motor systems (upper and 
lower extremity muscle strength and joint flexibility). ${ }^{1}$ Moreover, postural control and its adaptation to the environment are based on background postural tone and on postural reflexes or reactions, which are considered to originate from inputs from the visual and vestibular systems and from the somatosensory system, with inputs at the level of the different body segments. Postural tone is predominantly observed at the level of the limbs, back and neck extensor muscles, and the masseter muscle of the jaw. The main force vector of these muscles counteracts the effect of gravity when the subject is standing on a support surface. ${ }^{2}$

Postural sway should be minimal to maintain stable balance. According to a study by Baloh et al., ${ }^{3}$ there is increased postural sway with aging under both static and dynamic conditions. Deficits of posture and balance control can severely limit activities of daily living. Such deficits can lead to falls, which are a major source of morbidity and mortality in elderly persons. ${ }^{4}$ Therefore, prevention of falling is important, and many programs for preventing falls have been developed and proven their effectiveness. ${ }^{4-6}$ Evaluation of balance in a standing position is one of the tests used to predict the risk of falling. Clinical tests for evaluation of balance include the Tinetti test, Berg balance scale, and tests using a force plate as a quantitative method for balance evaluation. Tests using a force plate are objective and quantitative, but there are various test methods according to each laboratory, and a standardized method has not yet been developed..$^{7-10}$ There are several systems and parameters that use a force plate, and only a few clinical standard levels have been reported. ${ }^{11,12}$

This study aimed to investigate a possible standardized method by comparing results according to feet width, and to identify factors affecting the test results of a quiet standing balance evaluation conducted by posturography in a normal person.

\section{MATERIALS AND METHODS}

\section{Subjects}

The study cohort consisted of 100 healthy people (50 males, 50 females) aged between 21 and 69 years. Subjects who were taking medicines which could influence balance ability, and those with brain or neural disease, musculoskeletal or other medical problems were excluded. All participants received a satisfactory explanation of the study's object and methods. This study was initiated after receiving approval from the Institutional Review Board (IRB) at our hospital.

\section{Methods}

Balance evaluation tool: A commercially available computer-based system Good Balance Evaluator ${ }^{\circledR}$ (Metitur Ltd., Jyväskylä, Finland) was used for the force plate test. The main component of the system includes an equilateral triangular force plate (width $800 \mathrm{~mm}$, height $900 \mathrm{~mm}$ ) with strain gauge transducers at each corner of the plate, a power supply, and a computer. The analogue signals of the strain gauge transducers are converted to digits by 24-bit, 3-channel A/D-converters (sampling frequency $=50 \mathrm{~Hz}$ ). The outcome variables were distance $(\mathrm{mm})$, mean speed $(\mathrm{mm} / \mathrm{s})$, and the velocity moment $\left(\mathrm{mm}^{2} / \mathrm{s}\right)$ of movement of the center of pressure (COP). Mediolateral speed (ML-S, $\mathrm{mm} / \mathrm{s}$ ) and anteroposterior speed (AP-S, mm/s) were the average speeds of each mediolateral and anteroposterior pathway of the COP. Higher ML-S and AP-S values indicated faster swaying of the body and poorer balance. Mediolateral extent (ML-E) and anteroposterior extent (AP-E) were the total extents of the line in each mediolateral and anteroposterior pathway of the COP. Higher ML-E and AP-E values indicated greater swaying of the body and poorer balance. Velocity moment (VM) was the moment of speed from the COP pathway. A higher VM meant more body sway and was another indication of poorer balance.

Measurement of quiet standing balance: To minimize error, the subjects were well-informed about the methods of the measurement. Subjects removed their shoes and stood on the force plate in 3 different postures, according to the distance between both of their feet: 1) feet width was same as shoulder width (test 1),2) feet width was same as half of the shoulder width (test 2), 3) feet width was decided by the subject's comfort, to minimize their movement on the force plate. Feet width means the distance between the midline of both heels, and shoulder width is the distance between both acromial angles. Subjects stood at attention looking straight ahead toward a point on the monitor, with both arms in a natural position (Fig. 1). The balance evaluation was started with the subjects' attempting to balance themselves without swaying for 30 seconds. Each subject performed 6 tests 
from test 1 to test 3 , once with eyes open and once with eyes closed. The resting time between each test was 30 seconds.

SPSS version 15.0 was used for all analyses. Differences in balance indices between test methods, gender, and eye status (open or closed) were analyzed using the Paired t-test. The correlations between balance indices, age, and height were analyzed by the Pearson correlation test.

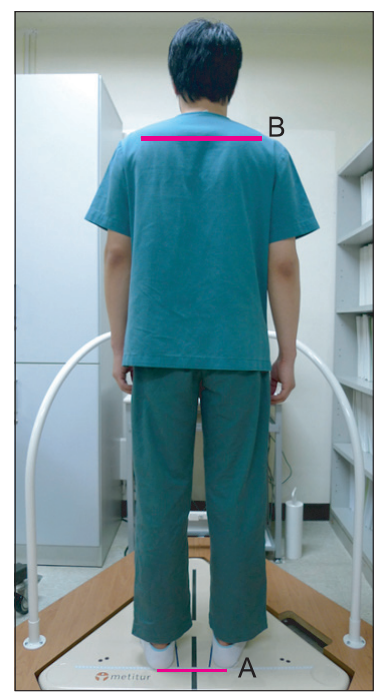

Fig. 1. (A) An example of a quiet standing balance test conducted using the Good Balance Evaluator is shown. Feet width is distance between the centers of both heels. (B) Shoulder width is distance between both acromial angles.
Statistical significance was assumed at $\mathrm{p}<0.01$.

\section{RESULTS}

The mean age of subjects in this study was $44.1 \pm 14.5$ years, their mean shoulder width was $38.4 \pm 3.0 \mathrm{~cm}$, mean height was $164.7 \pm 9.4 \mathrm{~cm}$, and their mean weight was $61.8 \pm 10.7 \mathrm{~kg}$. The mean percentage of feet width decided by the subjects' comfort was $56.5 \pm 15.7 \%$ of mean shoulder width (Table 1). There was no significant difference between results obtained from men and women (Table 2). The balance parameters evaluated in the eyes closed condition showed significantly lower values than in the eyes open condition $(\mathrm{p}<0.01)$.

\section{Distance and speed of COP movement}

AP-E did not show differences between the 3 test methods, but ML-E showed significant differences between the test methods. ML-E of test 1 was longer than

Table 1. Demographics of Subjects $(n=100)$

\begin{tabular}{lc}
\hline & Mean \pm SD (range) \\
\hline $\begin{array}{l}\text { Ratio of comfortable feet } \\
\text { width to shoulder width }(\%)\end{array}$ & $56.5 \pm 15.7(21.1-126.3)$ \\
Height $(\mathrm{cm})$ & $164.7 \pm 9.4(148-186)$ \\
Weight $(\mathrm{kg})$ & $61.8 \pm 10.7(39-87)$ \\
Age (years) & $44.1 \pm 14.5(21-69)$ \\
\hline
\end{tabular}

SD: Standard deviation

Table 2. Comparison of Results between Males and Females

\begin{tabular}{|c|c|c|c|c|c|c|}
\hline & \multicolumn{3}{|c|}{ Male } & \multicolumn{3}{|c|}{ Female } \\
\hline & Test 1 & Test 2 & Test 3 & Test 1 & Test 2 & Test 3 \\
\hline ML-E, EO (mm) & $121.2 \pm 31.6$ & $87.5 \pm 25.4$ & $90.9 \pm 25.4$ & $120.8 \pm 36.0$ & $90.2 \pm 26.0$ & $96.4 \pm 35.0$ \\
\hline ML-E, EC (mm) & $141.0 \pm 34.1$ & $104.8 \pm 29.3$ & $108.7 \pm 32.5$ & $139.0 \pm 38.9$ & $112.7 \pm 32.8$ & $120.1 \pm 47.1$ \\
\hline AP-E, EO (mm) & $146.6 \pm 31.1$ & $141.7 \pm 33.1$ & $146.2 \pm 39.5$ & $143.9 \pm 42.4$ & $141.2 \pm 35.1$ & $150.0 \pm 40.2$ \\
\hline $\mathrm{AP}-\mathrm{E}, \mathrm{EC}(\mathrm{mm})$ & $227.4 \pm 62.9$ & $219.2 \pm 70.4$ & $221.7 \pm 72.5$ & $246.3 \pm 54.6$ & $245.2 \pm 63.2$ & $256.5 \pm 80.9$ \\
\hline $\mathrm{ML}-\mathrm{S}, \mathrm{EO}(\mathrm{mm} / \mathrm{s})$ & $4.1 \pm 1.1$ & $2.9 \pm 0.9$ & $3.1 \pm 0.9$ & $4.0 \pm 1.2$ & $3.0 \pm 0.9$ & $3.2 \pm 1.2$ \\
\hline ML-S, EC (mm/s) & $4.8 \pm 1.4$ & $3.5 \pm 1.0$ & $3.7 \pm 1.1$ & $4.7 \pm 1.4$ & $3.8 \pm 1.1$ & $4.1 \pm 1.7$ \\
\hline AP-S, EO $(\mathrm{mm} / \mathrm{s})$ & $4.7 \pm 1.1$ & $4.6 \pm 1.2$ & $4.7 \pm 1.4$ & $5.2 \pm 1.4$ & $5.1 \pm 1.4$ & $5.3 \pm 1.4$ \\
\hline AP-S, EC $(\mathrm{mm} / \mathrm{s})$ & $7.8 \pm 2.4$ & $7.4 \pm 2.4$ & $7.6 \pm 2.8$ & $8.4 \pm 2.2$ & $8.5 \pm 2.6$ & $8.8 \pm 3.2$ \\
\hline $\mathrm{VM}, \mathrm{EO}\left(\mathrm{mm}^{2} / \mathrm{s}\right)$ & $7.2 \pm 3.8$ & $6.3 \pm 3.1$ & $6.5 \pm 4.2$ & $8.4 \pm 4.6$ & $7.7 \pm 3.8$ & $8.1 \pm 4.8$ \\
\hline $\mathrm{VM}, \mathrm{EC}\left(\mathrm{mm}^{2} / \mathrm{s}\right)$ & $11.2 \pm 4.8$ & $10.1 \pm 5.8$ & $10.6 \pm 5.6$ & $13.2 \pm 6.3$ & $12.1 \pm 5.6$ & $13.8 \pm 7.9$ \\
\hline
\end{tabular}

Test 1: Stance is same as shoulder width, Test 2: Stance is same as half of shoulder width, Test 3: Stance is determined by subject's comfort, EO: Eyes open, EC: Eyes closed, ML-E: Mediolateral extent, AP-E: Anteroposterior extent, ML-S: Mediolateral speed, AP-S: Anteroposterior speed, VM: Velocity moment 
Table 3. Results of Standing Balance Evaluation by Test Method

\begin{tabular}{lcccccc}
\hline & Test 1 EO & Test 2 EO & Test 3 EO & Test 1 EC & Test 2 EC & Test 3 EC \\
\hline ML-E (mm) & $121.0 \pm 33.7$ & $88.9 \pm 25.6^{*}$ & $93.6 \pm 30.6^{\dagger}$ & $140.0 \pm 36.4$ & $108.7 \pm 31.2^{*}$ & $114.5 \pm 40.7^{\dagger}$ \\
AP-E $(\mathrm{mm})$ & $145.7 \pm 38.1$ & $143.0 \pm 38.3$ & $148.6 \pm 40.3$ & $236.9 \pm 59.4$ & $232.2 \pm 67.8$ & $239.1 \pm 78.4$ \\
ML-S (mm/s) & $4.0 \pm 1.2$ & $3.0 \pm 0.9^{*}$ & $3.1 \pm 1.0^{\dagger}$ & $4.8 \pm 1.4$ & $3.6 \pm 1.0^{*}$ & $3.9 \pm 1.5^{\dagger}$ \\
AP-S $(\mathrm{mm} / \mathrm{s})$ & $4.9 \pm 1.3$ & $4.8 \pm 1.4$ & $5.0 \pm 1.4$ & $8.1 \pm 2.3$ & $8.0 \pm 2.6$ & $8.2 \pm 3.0$ \\
VM $\left(\mathrm{mm}^{2} / \mathrm{s}\right)$ & $7.8 \pm 4.2$ & $7.0 \pm 3.6$ & $7.3 \pm 4.6$ & $12.2 \pm 5.7$ & $11.1 \pm 5.8$ & $12.1 \pm 7.0$ \\
\hline
\end{tabular}

Test 1: Stance is same as shoulder width, Test 2: Stance is same as half of shoulder width, Test 3: Stance is determined by subject's comfort, EO: Eyes open, EC: Eyes closed, ML-E: Mediolateral extent, AP-E: Anteroposterior extent, ML-S: Mediolateral speed, AP-S: Anteroposterior speed, VM: Velocity moment

${ }^{*} \mathrm{p}<0.01$ by paired T-test, comparison between test 1 and $2,{ }^{\dagger} \mathrm{p}<0.01$ by paired T-test comparison between test 1 and 3

those of tests 2 and 3 with eyes open and closed $(\mathrm{p}<0.01)$. There was no significant difference in ML-E between test 2 and test 3 (Table 3). AP-S did not show differences between the 3 test methods, but the ML-S of test 1 was faster than those of tests 2 and 3 with eyes open and closed $(\mathrm{p}<0.01)$ (Table 3).

\section{Velocity moment}

The velocity moment of test 1 was larger than those of other tests, but there was no statistical significance. There were also no significant differences between tests 2 and 3 (Table 3).

\section{Correlation between balance indices, age, and height}

The AP-E and AP-S of all 3 test methods increased as the ages of the subjects increased $(\mathrm{p}<0.01)$. Also, the ML-E with eyes closed and the velocity moments of tests 2 and 3 showed a tendency toward poor standing balance as the ages of the subjects increased (Table 4).

Because an individual's height tends to decrease with increasing age, we analyzed the correlation between balance indices and the height of a subject only in subjects aged between their twenties and thirties. There was no significant correlation in all balance indices (Table 5).

\section{DISCUSSION}

Maintenance of balance relies on the harmonious integration and coordination of multiple body systems including the vestibular, visual, auditory, sensory, and autonomic systems. ${ }^{13}$ The information from these different end organs is integrated in the central nervous system (CNS), an appropriate response is formulated,
Table 4. Correlation Coefficient (r) between Age and Results of Standing Balance

\begin{tabular}{lcll}
\hline & Test 1 & Test 2 & Test 3 \\
\hline ML-E, EO $(\mathrm{mm})$ & -0.046 & 0.070 & 0.073 \\
ML-E, EC $(\mathrm{mm})$ & 0.203 & $0.261^{*}$ & $0.302^{*}$ \\
AP-E, EO $(\mathrm{mm})$ & $0.256^{*}$ & $0.401^{*}$ & $0.356^{*}$ \\
AP-E, EC $(\mathrm{mm})$ & $0.379^{*}$ & $0.531^{*}$ & $0.456^{*}$ \\
ML-S, EO $(\mathrm{mm} / \mathrm{s})$ & -0.060 & 0.064 & 0.095 \\
ML-S, EC $(\mathrm{mm} / \mathrm{s})$ & 0.155 & 0.230 & $0.271^{*}$ \\
AP-S, EO $(\mathrm{mm} / \mathrm{s})$ & $0.270^{*}$ & $0.417^{*}$ & $0.370^{*}$ \\
AP-S, EC $(\mathrm{mm} / \mathrm{s})$ & $0.393^{*}$ & $0.514^{*}$ & $0.486^{*}$ \\
\hline VM, EO $\left(\mathrm{mm}^{2} / \mathrm{s}\right)$ & 0.075 & $0.280^{*}$ & 0.094 \\
VM, EC $\left(\mathrm{mm}^{2} / \mathrm{s}\right)$ & 0.183 & $0.286^{*}$ & $0.319^{*}$ \\
\hline
\end{tabular}

Test 1: Stance is same as shoulder width, Test 2: Stance is same as half of shoulder width, Test 3: Stance is determined by subject's comfort, EO: Eyes open, EC: Eyes closed, ML-E: Mediolateral extent, AP-E: Anteroposterior extent, ML-S: Mediolateral speed, AP-S: Anteroposterior speed, VM: Velocity moment

${ }^{*} \mathrm{p}<0.01$ by Pearson correlation test

and the musculoskeletal system is directed to perform the appropriate head, eye, trunk, and limb movements to maintain posture. ${ }^{14}$ Pajala et al. ${ }^{7}$ reported that wide feet width could compensate impaired balance by adding more support to the base, and Benvenuti et al. ${ }^{15}$ suggested that narrow feet width could increase instability by flexion of the hip joint to maintain balance. In this study, COP movement (ML-E and ML-S) was greater when the subject's feet width was as wide as the shoulder width than half of the shoulder width, or at a comfortable width. Indices of balance evaluation on a force plate are expressed by degrees of overall performance of multiple systems to provide balance 
Table 5. Correlation Coefficient ( $\mathrm{r}$ ) between Height and Results of Standing Balance (Age Range is 20s to 30s)

\begin{tabular}{lrrr}
\hline & Test 1 & Test 2 & Test 3 \\
\hline ML-E, EO $(\mathrm{mm})$ & -0.031 & 0.043 & 0.037 \\
ML-E, EC $(\mathrm{mm})$ & 0.038 & -0.095 & 0.082 \\
AP-E, EO $(\mathrm{mm})$ & -0.141 & -0.086 & 0.037 \\
AP-E, EC $(\mathrm{mm})$ & 0.178 & 0.129 & 0.160 \\
\hline ML-S, EO $(\mathrm{mm} / \mathrm{s})$ & -0.014 & 0.031 & 0.033 \\
ML-S, EC $(\mathrm{mm} / \mathrm{s})$ & 0.143 & -0.091 & 0.066 \\
AP-S, EO $(\mathrm{mm} / \mathrm{s})$ & -0.143 & -0.079 & 0.034 \\
AP-S, EC $(\mathrm{mm} / \mathrm{s})$ & 0.179 & 0.083 & 0.173 \\
VM, EO $\left(\mathrm{mm}^{2} / \mathrm{s}\right)$ & -0.072 & -0.044 & -0.072 \\
VM, EC $\left(\mathrm{mm}^{2} / \mathrm{s}\right)$ & 0.134 & 0.039 & 0.061 \\
\hline
\end{tabular}

Test 1: Stance is same as shoulder width, Test 2: Stance is same as half of shoulder width, Test 3: Stance is determined by subject's comfort, EO: Eyes open, EC: Eyes closed, ML-E: Mediolateral extent, AP-E: Anteroposterior extent, ML-S: Mediolateral speed, AP-S: Anteroposterior speed, VM: Velocity moment

of the subject. Several pathways of the CNS including the pyramidal, extrapyramidal, reticulospinal, medial vestibulospinal, and lateral vestibulospinal tracts influence balance by controlling voluntary movement and muscle tone. Also, the peripheral afferent system and cerebral cortex perform their roles in balance by providing sensory feedback, and receipt and transfer of information. ${ }^{14,16,17}$ The semicircular canal, utricular, and saccular maculae of the vestibular system, and the visual system also participate in balance control. All of these various systems should function normally to minimize COP movement during evaluation of quiet standing balance on a force plate. We believe that the reason the greatest COP movement was in test 1 is that the subjects contracted their distal lower muscles (peroneus longus, gastrocnemius, etc) rather than their antigravity axial muscles, which are the main muscles used in balance control, to maintain balance with their feet spread widely apart. This means that the indices for evaluation of quiet standing balance on the force plate will appear as if balance ability is impaired. Although excessively wide feet width can produce a stable position, it creates great COP movement by inappropriate contraction of the distal lower muscles. These results can produce a coveringeffect of balance impairment when the evaluation of multiple systems participating in balance control is made on a force plate.

This study shows that balance indices including distance and speed of COP movement were better when the feet width of a subject equaled half of the shoulder width, or was a comfortable width, rather than a full shoulder width. COP movement was smaller in a position with half a shoulder width than in a position with a comfortable width, but it is difficult to conclude that half of a shoulder width produces a more stable result because there was no statistical significance. Also, the mean percentage of feet width decided by the subject's comfort was $56.5 \pm 15.7 \%$ of the shoulder width. This means the comfortable width was not very different from the half shoulder width.

Therefore, we think that an appropriate method for evaluation of quiet standing balance includes making feet width the same as half the shoulder width, because that measurement can be made objectively and will produce relatively better results.

The results of many balance indices were poor as the ages of the subjects became older. Several studies have reported that balance ability decreases in old age ${ }^{18-20}$ Hair cell loss in the ampula, neuronal loss in the vestibular nuclei, and visual impairment due to cataracts and glaucoma occurs with aging. ${ }^{21,22}$ In addition, balance impairment in old age can be induced by sensory impairment due to arthritis, diabetes, vitamin B12 deficiency, atherosclerosis, and musculoskeletal impairment due to sarcopenia, joint mobility restriction, and decreased postural response. Orthostatic hypotension related to medications, and decreases of concentration and alertness also contribute to balance impairment in old age. ${ }^{23,24}$ There was no difference in balance indices between men and women. This result is consistent with those of previous studies which compared the balance abilities of men and women. ${ }^{25,26}$ The mean height of subjects was $171.3 \pm 7.3$ $\mathrm{cm}$ for males and $158.1 \pm 5.9 \mathrm{~cm}$ for females.. However, we think that the difference did not affect the results of the evaluation because height and balance ability were not significantly correlated. Also we could verify that visual compensation clearly contributed to balance by the statistical difference observed in the results between positions with eyes open and eyes closed.

The Good Balance Evaluator ${ }^{\circledR}$ used in this study converts the results of a standing balance evaluation performed during 30 seconds to numerical values. For the best results, subjects are required to stand quietly 
and minimize movement with substantial concentration. The subjects should concentrate on static standing for 180 seconds during 6 evaluations to minimize COP movement. The results of an evaluation could be made worse by a momentary loss of posture due to a lack of concentration. This could also increase the range of statistical error among subjects. Without a subject's active cooperation and concentration during evaluation, the results of a test could be made worse, regardless of the subject's ability to balance. This could be one drawback of conducting a balance evaluation using equipment with a force plate. To compensate for this limitation, re-evaluation with inducing concentration could be considered in case that test results are suspicious of lack of concentration in comparison with results of clinical balance evaluation tools, such as, Tinetti test, Berg balance scale.

Not all age groups were included in this study, because we did not enroll subjects aged $<20$ years or $>69$ years. Also, this study evaluated only quiet standing balance on a fixed force plate and not clinical dynamic balance, which could be a limitation of the study. A further study including dynamic standing balance on a moving force plate and a broader range of age groups is needed to properly evaluate the role of posture in maintaining balance.

\section{CONCLUSION}

COP movements were increased with age and when subjects closed their eyes during evaluation of quiet standing balance conducted by posturography. Gender and height did not affect test results. We suggest that an appropriate method to test balance is by standing on a force plate with feet width the same as half the shoulder width, because many subjects felt comfortable in this posture and it presented a relatively accurate measurement of balance capacity. The results of this study are expected to be used as standard data in further evaluations of quiet standing balance in normal subjects.

\section{REFERENCES}

1. Gonzales EG, Myers SJ, Edelstein JE, Lieberman JS, Downey JA. Downey and Darling's physiological basis of rehabilitation medicine, 3rd ed, Boston: Butter-
worth-Heinemann, 2001, 565-566

2. Bronstein AM, Brandt T, Woollacott M. Clinical disorders of balance posture and gait, 1st ed, London: Arnold, 1996, 2-3

3. Baloh RW, Fife TD, Zwerling L, Socotch T, Jacobson K, Bell T, Beykirch K. Comparison of static and dynamic posturography in young and older normal people. J Am Geriatr Soc 1994; 42: 405-412

4. Smulders E, Weerdesteyn V, Groen BE, Duysens J, Eijsbouts A, Laan R, van Lankveld W. Efficacy of a short multidisciplinary falls prevention program for elderly persons with osteoporosis and a fall history: a randomized controlled trial. Arch Phys Med Rehabil 2010; 91: 1705-1711

5. Lim JY, Lim JY, Park JA, Oh MK, Park WB, Kang EK, Shin HI, Paik NJ. Short-term and long-term effects of integrated fall prevention program in the Korean elderly. J Korean Acad Rehab Med 2010; 34: 451-457

6. Nardone A, Godi M, Artuso A, Schieppati M. Balance rehabilitation by moving platform and exercises in patients with neuropathy or vestibular deficit. Arch Phys Med Rehabil 2010; 91: 1869-1877

7. Pajala S, Era P, Koskenvuo M, Kaprio J, Törmäkangas $\mathrm{T}$, Rantanen T. Force platform balance measures as predictors of indoor and outdoor falls in communitydwelling women aged 63-76 years. J Gerontol A Biol Sci Med Sci 2008; 63: 171-178

8. Kim CR, Chun MH, Lee GA. Assessments of balance control using tetra-ataxiametric posturography. J Korean Acad Rehab Med 2009; 33: 429-435

9. Sihvonen S, Sipilä S, Taskinen S, Era P. Fall incidence in frail older women after individualized visual feedback-based balance training. Gerontology 2004; 50: 411-416

10. Panzer VP, Bandinelli S, Hallett M. Biomechanical assessment of quiet standing and changes associated with aging. Arch Phys Med Rehabil 1995; 76: 151-157

11. Era P, Sainio P, Koskinen S, Haavisto P, Vaara M, Aromaa A. Postural balance in a random sample of 7,979 subjects aged 30 years and over. Gerontology 2006; 52: 204-213

12. Riley PO, Benda BJ, Gill-Body KM, Krebs DE. Phase plane analysis of stability in quiet standing. J rehabil Res Dev 1995; 32: 227-235

13. Matsumura BA, Ambrose AF. Balance in the elderly. Clin Geriatr Med 2006; 22: 395-412 
14. Konrad HR, Girardi M, Helfert R. Balance and aging. Laryngoscope 1999; 109: 1454-1460

15. Benvenuti F, Mecacci R, Gineprari I, Bandinelli S, Benvenuti E, Ferrucci L, Baroni A, Rabuffetti M, Hallett M, Dambrosia JM, et al. Kinematic characteristics of standing disequilibrium: reliability and validity of a posturographic protocol. Arch Phys Med Rehabil 1999; 80: 278-287

16. Shumway-Cook A, Horak FB. Rehabilitation strategies for patients with vestibular deficits. Neurol Clin 1990; 8: 441-457

17. Loram ID, Lakie M. Human balancing of an inverted penundulum: position control by small, ballisticlike, throw and catch movements. J physiol 2002; 540: 1111-1124

18. Rogers MW, Mille ML. Lateral stability and falls in older people. Exerc Sport Sci Rev 2003; 31: 182-187

19. Herdman SJ, Schubert MC, Tusa RJ. Strategies for balance rehabilitation: fall risk and treatment. Ann N Y Acad Sci 2001; 942: 394-412

20. Whipple R, Wolfson L, Derby C, Singh D, Tobin J.
Altered sensory function and balance in older persons. J Gerontol 1993; 48: 71-76

21. Rosenhall U. Degenerative patterns in the aging human vestibular neuro-epithelia. Acta Otolaryngol 1973; 76: 208-220

22. Harwood RH. Visual problems and falls. Age Ageing 2001; 30: 13-18

23. Verghese J, Bieri PL, Gellido C, Schaumburg HH, Herskovitz S. Peripheral neuropathy in young-old and old-old patients. Muscle Nerve 2001; 24: 1476-1481

24. Woollacott M, Inglin B, Manchester D. Response preparation and posture control. Neuromuscular changes in the older adult. Ann N Y Acad Sci 1988; 515: 42-53

25. Wolfson L, Whipple R, Derby CA, Amerman P, Nashner L. Gender differences in the balance of healthy elderly as demonstrated by dynamic posturography. J Gerontol 1994; 49: M160-167

26. Røgind H, Lykkegaard JJ, Bliddal H, DanneskioldSamsøe B. Postural sway in normal subjects aged 2070 years. Clin Physiol Funct Imaging 2003; 23: 171-176 